\title{
Erratum to: Effects of Dietary Selenomethionine on Cutthroat Trout (Oncorhynchus clarki bouvieri) Growth and Reproductive Performance Over a Life Cycle
}

\author{
Ronald W. Hardy • Libbie L. Oram • \\ Gregory Möller
}

Published online: 19 November 2009

(C) Springer Science+Business Media, LLC 2009

\section{Erratum to: Arch Environ Contam Toxicol DOI 10.1007/s00244-009-9392-x}

In 4th and 14th line of abstract, the text says " $2,4,6,8$, or $10 \mu \mathrm{g}$ selenomethionine/g diet" and " $4 \mu \mathrm{g}$ selenomethionine/kg". It should be " $2,4,6,8$, or $10 \mu \mathrm{g} \mathrm{Se} / \mathrm{g}$ diet as selenomethionine." and " $4 \mu \mathrm{g} \mathrm{Se/g} \mathrm{diet} \mathrm{as} \mathrm{selenomethionine".}$

Abstract A 2.5 year feeding trial was conducted in which cutthroat trout (Oncorhynchus clarki bouvieri) were fed either a basal diet $(1.2 \mu \mathrm{g} \mathrm{Se} / \mathrm{g}$ diet $)$ or the basal diet supplemented with $2,4,6,8$, or $10 \mu \mathrm{g} \mathrm{Se} / \mathrm{g}$ diet as selenomethionine from $1 \mathrm{~g}$ weight to maturation. After 44 weeks of feeding, a subsample of fish was removed from dietary treatment groups and fed the basal diet for an additional 32 weeks. Concentrations of Se in whole fish and eggs increased in proportion to dietary Se intake, but no differences in growth, feed intake, survival, or egg hatchability were observed among dietary groups. Cranialfacial deformities in second generation offspring were less than $6 \%$ in all treatment groups except for fish fed the diet supplemented with $4 \mu \mathrm{g} \mathrm{Se} / \mathrm{g}$ diet, where a $9.2 \%$ incidence was observed. Fish switched from selenomethionine supplemented diets to the basal diet lost $\mathrm{Se}$, calculated as $\mu \mathrm{g}$ Se lost/g weight gain, at $1.01,2.84,4.42$, and 4.42 for dietary treatment groups $3,4,5$, and 6 , respectively. Results suggest no toxicity of dietary selenomethionine up to $10 \mu \mathrm{g} \mathrm{Se} / \mathrm{g}$ supplemented diet and that with total life cycle exposure, cutthroat trout increase Se excretion to maintain whole-body concentrations below toxic levels.

The online version of the original article can be found under doi: 10.1007/s00244-009-9392-x.

R. W. Hardy ( $\square)$

Aquaculture Research Institute, University of Idaho,

3059F National Fish Hatchery Road, Hagerman,

ID 83332, USA

e-mail: rhardy@uidaho.edu

L. L. Oram · G. Möller

Environmental Science Program, University of Idaho,

Moscow, ID 83844-1052, USA

L. L. Oram · G. Möller

School of Food Science, University of Idaho, Moscow,

ID 83844-1052, USA 